\title{
Reconstituição experimental da parede torácica de gatos com implante heterógeno de cartilagem auricular conservada em glicerina a $98 \%$
}

\author{
Experimental reconstitution of the cat's thoracic wall with dog conchal cartilage \\ implant preserved in $\mathbf{9 8 \%}$ glycerin
}

\author{
Josaine Cristina da Silva Rappeti ${ }^{1}$ Ney Luis Pippi ${ }^{2}$ Emerson Antonio Contesini ${ }^{3}$ \\ Saulo Tadeu Lemos Pinto Filho ${ }^{4}$ Simone Dias de Lima Alves ${ }^{4}$ Adriana Lücke Stigger $^{5}$ \\ Adriana Wolf Wander ${ }^{6}$ Miryane Franco Ercolani da Silva ${ }^{6}$ Fabíola Dalmolin $^{6}$ Juliano Thomaz $^{6}$
}

RESUMO

Com o objetivo de testar o implante de cartilagem auricular heteróloga conservada em glicerina a 98\% como alternativa para reparar defeitos na parede torácica em felinos, foram estudados doze animais adultos, sendo distribuidos em dois grupos GI e GII, e avaliados após 60 dias de pósoperatório. Todos os animais foram submetidos à ressecção costal na porção média do tórax abrangendo a 7ạ , $8^{\underline{a}}$ e $9^{\underline{a}}$ costelas e posterior implante de cartilagem conchal heteróloga conservada em glicerina a 98\%. No GI, foi preservada a musculatura adjacente, já no GII, a musculatura foi retirada. Os animais foram avaliados clinicamente no pós-operatório $e$, ao final do periodo, submetidos à eutanásia e necropsia para avaliação macroscópica e microscópica da região do implante. Observou-se proliferação de tecido fibrovascular neovascularizado sobre o implante, com aderência pulmonar e diafragmática em algumas das unidades experimentais. $O$ implante de cartilagem heteróloga conservado em glicerina a 98\% pode ser utilizado para reconstrução de parede costal cujo defeito abranja o espaço de parte de três costelas. O implante em 60 dias é substituido por tecido cicatricial, sem apresentar sinais clínicos de rejeição.

Palavras-chave: parede torácica, cartilagem conchal, gato.

\section{ABSTRACT}

Twelve adult cats were divided in groups GI and GII with the objective of testing a dog auricular cartilage implant conserved in $98 \%$ glycerin as an alternative to repair thoracic wall defects. All animals were submitted to a resection of the medial portion of the thorax by removal of the $7^{\text {th }}, 8^{\text {th }}$ and $9^{\text {th }}$ ribs and posterior cartilage implantation. GI had the adjacent musculature preserved and in GII cat's had it removed. The animals were clinically evaluated in the post operative period and after sixty days submitted to euthanasia for microscopic evaluation of the implanted local. Proliferation of granulation tissue and neomorph over the implant was observed in all animals and some had lung and diaphragm adherence. The heterograft cartilage implant conserved in $98 \%$ glycerin can be used for reconstruction of the thoracic wall when defects do not exceed the size of three ribs. In sixty days the cat's cartilage implant will be substituted by scar tissue with no signs of rejection.

Key words: toracic wall, conchal cartilage, cat.

\section{INTRODUÇÃO}

O tratamento das neoplasias e infecções crônicas da parede torácica requer excisão radical dos tecidos envolvidos (BRASMER, 1971). Segundo BRIGHT (1986), dentre as indicações, estão inclusas além das neoplasias, o traumatismo extensivo às costelas e musculatura adjacente e as infeções micóticas e bacterianas não responsivas ao tratamento terapêutico.

${ }^{1}$ Médico Veterinário, Mestre, Doutorando do Programa de Pós-graduação em Medicina Veterinária (PPGMV), Universidade Federal de Santa Maria (UFSM), Rua Barão do Triunfo, 700, 97010-000, Santa Maria, RS. E-mail:jorappeti@bol.com.br. Autor para correspondência.

${ }^{2}$ Médico Veterinário, PhD, Professor Adjunto, Departamento de Clínica de Pequenos Animais, UFSM.

${ }^{3}$ Médico Veterinário, Doutorando do PPGMV/UFSM.

${ }^{4}$ Médico Veterinário, Mestre pelo PPGMV/UFSM.

${ }^{5}$ Médico Veterinário, Mestre, Professor de Patologia da PUCRS - Uruguaiana e URCAMP-Alegrete, RS.

${ }^{6}$ Aluno do Curso de Medicina Veterinária da UFSM. 
Embora tumores primários de costelas não sejam comuns em cães e gatos (FOSSUM, 1997), os tumores malignos encontrados na parede torácica são os sarcomas (DELAY et al., 1994), osteossarcomas, condromas, fibrossarcomas e hemangiossarcomas (ORTON, 1998). FEENEY et al. (1982) observaram tumores primários e secundários na parede torácica que envolviam mais freqüentemente a região da 5a até a 9a costela em cães.

A reconstrução da parede do tórax deverá ser rígida, para que não ocorra movimento paradoxal durante a respiração (RUIZ et al., 1997) e deve também ficar hermeticamente fechada para evitar o pneumotórax (ORTON, 1998). Defeitos torácicos grandes, associados com traumas ou cirurgia oncológica agressiva incluindo três ou mais costelas podem acarretar uma instabilidade torácica (BONATH, 1996).

Nos casos de reconstrução caudal da parede torácica, ARONSOHN (1984) e ORTON (1995) utilizaram o avanço do músculo diafragma como uma forma de restabelecer a integridade do tórax após um traumatismo ou ressecção de tumor. Para estes autores, o local da lesão é importante para determinar o tipo de reparo necessário para reconstruir a integridade torácica. Autores como BRIGHT et al. (1982) e DELAY et al. (1994) citaram o emprego de epíploon com sucesso, em procedimentos de reconstituição de parede torácica, quando há defeitos com insuficiente tecido mole para seu revestimento. ABREU \& FIGUEIRA NETO (1997) descreveram que o uso do categute como sutura interna de gatos levou à reação inflamatória indesejável. ARAÚJO (1998) descreveu que o uso de alguns materiais para sutura interna como o náilon e a seda em gatos são contraditórios do ponto de vista da evolução cicatricial em feridas cirúrgicas.

Em alguns casos, os materiais biológicos utilizados para implantes em cirurgias reconstrutoras devem ser conservados. A glicerina tem sido muito utilizada para a preservação de materiais biológicos por apresentar boa disponibilidade, preparo simples e facilidade de emprego (PIGOSSI et al., 1971). ALVARENGA (1992) considerou a glicerina um agente fixador e desidratante de atuação rápida, agindo como poderoso anti-séptico com amplo espectro de ação, embora ele indique o uso de antibiótico ao reidratar o material utilizado. Já RAISER et al. (2000), que empregaram implantes tendíneos conservados em glicerina, asseguraram a anti-sepsia com solução de polivinilpirrolidona.

A cartilagem auricular tem sido utilizada por vários autores em cirurgias reparadoras, como se verifica nas pesquisas de CHEHUEN NETO et al.
(1991) que a utilizaram para restauração de traquéia, em PIGATTO et al. (1998) na esofagoplastia em cães, em CONTESINI et al. (2001a) na reparação traqueal em cães e CONTESINI et al. (2001b) no reparo tardio de fenda palatina em cães.

Devido à qualidade dos resultados obtidos por CHEHUEN NETO et al. (1991), PIGATTO et al. (1998), CONTESINI et al. (2001a), CONTESINI et al. (2001b) com a cartilagem auricular, procurou-se investigar o comportamento macro e microscópico da cartilagem auricular heteróloga conservada em glicerina a $98 \%$, para reconstituição de defeitos na parede torácica em gatos induzidos experimentalmente com ressecção costal.

\section{MATERIAL E MÉTODOS}

Para a experimentação, foram utilizados doze gatos adultos, hígidos, sendo três machos e nove fêmeas, sem raça definida, com peso médio de $3,4 \mathrm{~kg}$. Os animais foram submetidos a exame físico e alojados em gaiolas individuais por um período médio de 30 dias, no qual receberam alimentação e manejo.

As cartilagens auriculares de diferentes espessuras foram coletadas de cães com diversas raças e idades livres de doenças infecto-contagiosas encaminhados a eutanásia, em decorrência de acidentes traumáticos. Foram estocadas em frascos de vidro contendo glicerina a $98 \%$, em um período não inferior a trinta dias. Para terapia antimicrobiana profilática foi utilizada ampicilina sódica. A indução anestésica foi feita com tiletamina-zolazepam e a manutenção com halotano, sendo associada à anestesia epidural com morfina ou tramadol.

Os animais foram distribuídos em dois grupos experimentais: GI, constituído de 6 animais, submetidos à implante heterólogo e posterior sutura dos músculos grande dorsal, serrátil e intercostais e GII, também constituído de 6 animais submetidos à implante do mesmo tipo de estrutura conservada em glicerina a $98 \%$ porém com ressecção total dos músculos grande dorsal, serrátil e intercostais.

A abordagem cirúrgica foi realizada no terço médio do tórax; no GI, foi localizado o oitavo espaço intercostal, e posteriormente feita uma incisão na pele de $6 \mathrm{~cm}$ de comprimento sobre a costela, sendo incisados os músculos da região, delineando um quadrado entre a $7^{\mathrm{a}}$ e $9^{\mathrm{a}}$ costelas; em seguida, foi retirado o terço médio das 3 costelas. Foram elevados o periósteo da $7^{\mathrm{a}}$ e $9^{\mathrm{a}}$ costelas sendo removidos os segmentos ósseos da 7aa até a 9a costela, formando um defeito de a $3 \mathrm{X} 3 \mathrm{~cm}$ na parede torácica, pois os músculos intercostais também foram seccionados e retirados. 
A cartilagem utilizada para reparar o defeito ficou submersa em uma cuba com solução de polivinilpirrolidona e solução fisiológica de cloreto de sódio na proporção de 1:50 ( $1 \mathrm{ml}$ de solução de polivinilpirrolidona para $50 \mathrm{ml}$ de solução fisiológica de cloreto de sódio) por aproximadamente 15 minutos. Após, esta solução foi substituída por solução fisiológica de cloreto de sódio $0,9 \%$, sendo que o material permaneceu nesta por um período de aproximadamente 10 minutos antes de ser implantado. O implante foi remodelado para as dimensões necessárias à sua fixação no sítio receptor, tomandose o cuidado de deixar uma borda interna para fixá-lo ao tórax. A padronização foi feita através da utilização de um molde confeccionado a partir de um filme de raios-X.

Nos animais do GI, a sutura da cartilagem à parede torácica foi realizada com fio mononáilon de $\mathrm{n}^{\mathrm{o}}$ 3-0 agulhado com pontos em Wolff, incluindo o periósteo. Estas foram realizadas alternadamente de um lado e outro do sítio receptor. O implante foi adaptado de maneira que ficasse intrapleural. Todos os pontos foram fixados de maneira que fossem finalizados ao mesmo tempo (Figura1). Ao concluir o último nó entre as costelas, permaneceu uma pinça Halsted para que o anestesista fizesse a hiperinsuflação pulmonar; logo após foi retirada a pinça e finalizado o nó. A restituição da pressão negativa intratorácica foi feito no final da cirurgia no terço médio superior do $7^{\circ}$ espaço intercostal com "buterfly" de $\mathrm{n}^{-} \mathrm{19G}$, conectado a uma seringa de $60 \mathrm{ml}$ por meio de torneira de três vias. A sutura dos músculos adjacentes foram feitas com poliglactina 910 de no 3-0 agulhado por meio de um padrão festonado. A redução do espaço morto foi feita com o mesmo fio com pontos isolados simples. A síntese de pele foi realizada com fio de poliamida de $\mathrm{n}^{\circ} 0,25$ com o mesmo padrão de sutura do espaço morto.

Nos animais do GII, foram retirados os músculos grande dorsal, serrátil e intercostais dos espaços intercostais 7응 8ㅇ e 9o. Neste grupo, foi retirado o periósteo e a técnica de colocação do implante foi a mesma usada nos animais do GI exceto que os pontos de Wolff foram apoiados nas costelas adjacentes. Após a adaptação do implante, a pele foi suturada com pontos isolados simples com fio de poliamida de $\mathrm{n}^{\mathrm{o}}$ 0,25 .

Ao término da cirurgia, foi realizado bloqueio dos nervos intercostais com bupivacaína utilizando $0,3 \mathrm{ml}$ em cada animal em dois espaços intercostais. No período pós-operatório, os animais receberam ketoprofeno por 5 dias, sendo mantidos em observação clínica, em repouso durante 60 dias, com especial atenção à respiração, movimentos da parede torácica e cicatrização da ferida.

Decorrido o tempo estabelecido, os animais foram anestesiados com cetamina e xilazina e após foi utilizado cloreto de potássio para a eutanásia. Foram coletados segmentos do implante para avaliação macroscópica e microscópica e quanto ao aspecto e funcionalidade do mesmo. O material foi acondicionado em frascos com formol tamponado a $10 \%$ e preparado pela técnica de hematoxilinaeosina (HE) para análise histológica em microscopia óptica, quanto ao tipo de tecido neoformado e a reação inflamatória.

\section{RESULTADOS}

Todos os animais apresentaram boa evolução clínica após 48 horas de pós-operatório, sendo que apenas um animal pertencente ao GI apresentou deiscência de pele e outro do mesmo grupo apresentou movimento respiratório paradoxal, que retornou à normalidade 48 horas após. Apenas um animal do grupo GII apresentou seroma no pósoperatório. Todos os animais, nas primeiras 24 horas de pós-operatório, apresentavam respiração abdominal, retornando a tóraco-abdominal logo após este período.

No momento da sutura do implante no receptor, as cartilagens menos espessas foram facilmente manuseadas, entretanto ficaram enrugadas. As mais espessas apresentaram maior dificuldade para o manuseio, porém ficaram bem distendidas. $\mathrm{O}$ tamanho dos implantes e as técnicas de sutura usadas propiciaram que suas bordas ficassem no interior do tórax deixando-o bem vedado.

O tempo de preservação da cartilagem em glicerina foi eficiente, pois os animais não apresentaram sinais clínicos de rejeição ou infeção. As cartilagens conservadas em glicerina a $98 \%$ em temperatura ambiente, ao serem removidas dos frascos, apresentavam aspecto rígido, porém, com sua arquitetura tecidual macroscópica preservada. $\mathrm{O}$ tempo de reidratação foi eficaz, tornando a cartilagem maleável.

O defeito torácico permitiu uma boa técnica de reconstituição e manipulação das estruturas envolvidas no procedimento. A dimensão que abrangeu três costelas no terço médio do tórax permitiu avaliar a vedação através do implante de cartilagem no defeito. A hemostasia dos vasos intercostais foi feita através de ligaduras nos animais de maior peso corporal, sendo que, nos gatos menores, a mesma foi realizada por pinçamento e torção.

Ciência Rural, v. 33, n. 6, nov-dez, 2003. 


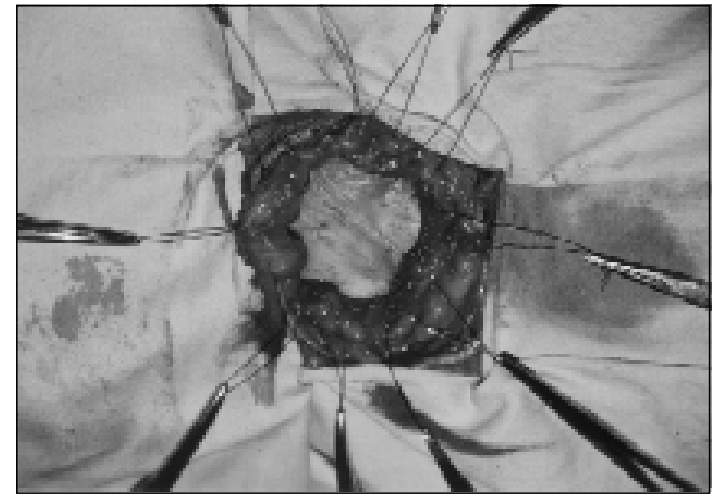

Figura 1 - Sutura do implante de cartilagem conchal no defeito da parede torácica de gato, com pontos em Wolff com fio de sutura mononailom 3-0. Os pontos de suturas estão reparados com pinças hemostáticas.

A sutura em pontos de Wolff, colocados alternadamente, fez com que o implante ficasse centralizado e, desta forma, ofereceu vantagem à técnica. $\mathrm{O}$ fio utilizado neste experimento foi $\mathrm{o}$ mononáilon de no 3-0 agulhado demonstrando ser seguro e eficiente, suportando a tensão existente entre o implante e a musculatura da parede torácica, já que nenhum animal apresentou deiscência no local do implante. O fio poliglactina 910 de no 3-0 agulhado utilizado com sutura festonada, na musculatura adjacente do GI, também demonstrou ser seguro.

O método de restauração da pressão negativa associando-se às duas técnicas foram eficazes, pois nenhum animal apresentou sinais clínicos de pneumotórax residual ou dificuldade respiratória no pós-operatório.

$\mathrm{Na}$ avaliação macroscópica, foram observadas aderência do implante com os pulmões em quatro gatos do GI e em todos os animais do GII. Dois gatos do GI apresentaram aderência do implante com o músculo diafragma. Em ambos os grupos, o implante apresentava-se envolto por tecido cicatricial. No gato no 2 do GI, a cartilagem apresentava vasos na região centro lateral, delimitando o tecido conjuntivo na cartilagem e as bordas do implante apresentaram-se espessadas. As amostras coletadas dos animais que receberam o implante mais espesso, apresentavam-se com as extremidades enrugadas. Ocorreu retração das margens das cartilagens mais espessas, sendo que as mais delgadas estavam bem aderidas na região pleural. O tecido de granulação invadiu o enxerto a partir da periferia. Um animal do GI apresentou vasos na região centro-lateral delimitando o tecido de granulação. No GI, houve uma maior quantidade de tecido de granulação na parte externa do tórax, quando comparado com dos animais do GII. Neste grupo, apenas um gato do experimento apresentou seroma no pós-operatório.

As análises histológicas revelaram que a cartilagem conchal estava circundada por tecido conjuntivo neovascularizado, envolta por células inflamatórias nononucleares. Um gato do GI apresentou células inflamatórias mononucleares em maior número, quando comparado com outras amostras próximo à cartilagem e ao redor do tecido conjuntivo neovascularizado (Figura 2). Em todas as análises realizadas, foi verificado que o implante de cartilagem conchal serviu de arcabouço para o tecido conjuntivo.

\section{DISCUSSÃO}

A cartilagem conchal é uma alternativa experimental, de fácil aquisição, com possível aplicabilidade prática na correção de defeitos da parede torácica, de baixo custo, quando comparado com os materiais sintéticos. A técnica para a reconstrução torácica proporcionou perfeita tensão, com rigidez adequada e, desta forma, diminuindo os problemas de tórax instável, o que corrobora com as afirmações de RUIZ et al. (1997). Para BONATH (1996), a malha de marlex tem como característica, alta resistência à tração permitindo ser fortemente distendida sobre o defeito; a cartilagem auricular apresenta as propriedades que os autores anteriores citaram, que é o de permitir ser fortemente distendida sobre o defeito, tendo ainda maleabilidade e resistência, tornando eficiente o seu emprego.

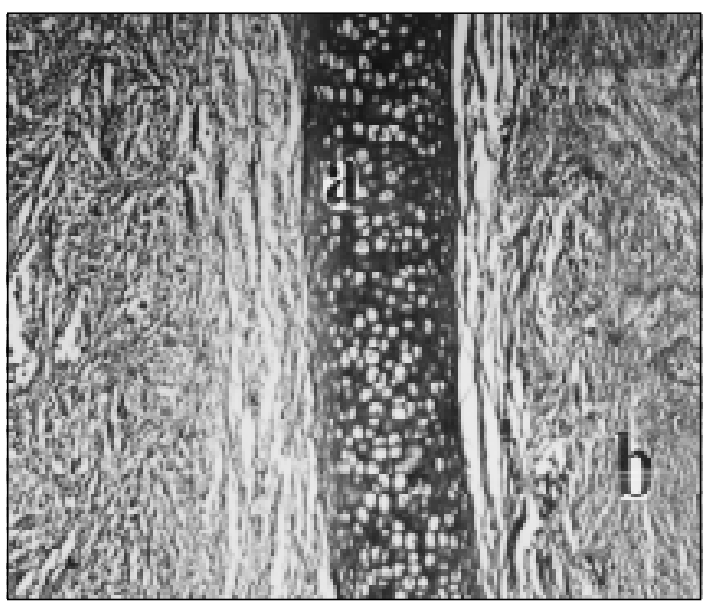

Figura 2 - Histopatológico com área do implante de cartilagem auricular conservada em glicerina a $98 \%$ após 60 dias de pós-operatório, aumento de 40x. A cartilagem auricular (a) e tecido inflamatório (b).

Ciência Rural, v. 33, n. 6, nov-dez, 2003. 
Optou-se pelo uso da glicerina a $98 \%$ como meio de preservação da cartilagem conchal devido às características descritas por PIGOSSI et al. (1971) como preservação da textura e aumento da resistência à tração, sem alterar o grau de elasticidade. ALVARENGA (1992) descreveu que, ao mesmo tempo que a glicerina reduz a antigenicidade, ela é um agente desidratante de ação rápida, agindo como um poderoso anti-séptico, tornando necessária a reidratação; o tempo sugerido pelo autor de 20 a 30 minutos foi importante, pois promoveu a hidratação e tornou a cartilagem mais maleável facilitando a sua manipulação; sua sugestão de empregar o uso de solução antibiótica na solução fisiológica foi substituída pela indicação de RAISER et al. (2000), que empregaram, em implantes tendíneos, polivinilpirrolidona com solução fisiológica de cloreto de sódio, durante 24 horas antes da implantação. A redução para 15 minutos foi eficaz, devido à cartilagem ser uma estrutura mais delgada comparada com o tendão.

O uso de antibiótico não foi necessário no pós-operatório tendo em vista uma excelente resposta dos animais, sem apresentar quaisquer sinais clínicos de infeção, indo de encontro a ARONSOHN (1984), que utilizou antibioticoterapia por oito dias.

A utilização do filme de raios-X, com as dimensões do enxerto de cartilagem sugerido por PIGATTO et al. (1998), proporcionou um padrão para o implante, embora nos gatos menores a cartilagem tenha ficado maior que o defeito, proporcionalmente aos gatos de maior peso corpóreo, permitindo aderência com o músculo diafragma. O local onde foi desenvolvido o defeito torácico, é uma região onde os tumores mais acometem a parede torácica segundo FEENEY et al. (1982).

Para prevenir o movimento paradoxal BRASMER (1971), acredita que se deve usar uma malha suficientemente rígida. A cartilagem utilizada tem como vantagem a sua rigidez, associada ao tecido de granulação que a invade, como se esse fosse um leito, contribuem para a estabilização evitando complicações no pós-operatório. Um dos animais em experimentação apresentou o movimento paradoxal que pode estar associado a traumatismos na musculatura adjacente e pele, segundo BONATH (1996). Esta complicação desapareceu em dois dias, corroborando as afirmações de BRIGHT (1986), ao descrever que qualquer movimento remanescente desta complicação desaparece dentro de três dias e, geralmente, não apresenta risco de vida ao paciente.

O material de sutura adequado para a reconstituição torácica, segundo FOSSUM (1997) e BRASMER (1971), deve ser monofilamento, não absorvível, como o polipropileno. BRIGHT (1986) recomendou o náilon agulhado que foi utilizado nesse experimento, demonstrando ser seguro, e de fácil manuseio suportando a diferença de pressão do tórax. BRIGHT (1986) preconiza sutura da musculatura adjacente com fios categute ou ácido poliglicólico. $\mathrm{O}$ fio de sutura utilizado na musculatura foi a poliglactina 910, que demonstrou ser seguro e de fácil manuseio e, segundo ABREU \& FIGUEIRA NETO (1997), o que produz menor reação inflamatória nos gatos. Os vasos intercostais dos animais com maior peso corporal tiveram que ser ligados, não sendo necessário para os gatos menores, como citou ARONSOHN (1984), que teve que ligar o suprimento sanguíneo arterial da área ressecada.

BRIGHT (1986) utilizou, na margem da malha de marlex, uma dobra para aumentar a resistência do material. A cartilagem, por ser estruturalmente rígida, não foi compatível com este procedimento, embora o seu diâmetro tenha sido suficiente para obter a resistência necessária para a reconstituição torácica como citado por BRASMER (1971). A opção de colocar todos os pontos e, após finalizar o nó, propiciou que o implante permanecesse no centro do defeito, diferindo de BRIGHT (1986), ao sugerir que os nós devem ser apertados logo que sejam implantados.

Segundo FOSSUM (1997), existem várias maneiras de restituir a pressão negativa como o selo d'água utilizando dois ou três frascos. Os métodos utilizados neste experimento, hiperinsuflação pulmonar e a técnica da torneira de três vias, demonstraram ser eficientes e de fácil execução. ARONSOHN (1984), BRIGHT et al. (1982), BRIGHT (1986), preconizaram o uso de tubo de penrose, deixando por três horas de pós-operatório a fim de evitar pneumotórax.

$\mathrm{Na}$ avaliação macroscópica, aos 60 dias de pós-operatório, a área do implante revelou, tecido fibrovascular na região, corroborando com os dados obtidos por BONATH (1996). BRIGHT et al. (1982) descreveram que a pleura parietal fica espessada e observa-se uma infiltração de tecido fibroso no local de enxertia. A aderência de vísceras, como o pulmão, ocorreu com o implante, fato este observado nos trabalhos de BRIGHT et al. (1982). Dos 12 animais avaliados, 10 apresentaram aderência com o pulmão e dois com o músculo diafragma, embora não apresentassem nenhum sinal clínico de descompensação.

$\mathrm{Na}$ avaliação microscópica, foram observados, tecido conjuntivo, vasos neoformados e infiltrado de células mononuleares, como citado por CONTESINI et al. (2001a), sugerindo fator de reparação.

Ciência Rural, v. 33, n. 6, nov-dez, 2003. 
Durante o pós-operatório até o dia das avaliações macroscópicas, foi observada evolução cicatricial satisfatória. Apenas um caso de deiscência de pontos de pele ocorreu, obtendo cicatrização por segunda intenção, semelhante ao que ocorreu com os animais usados no experimento de ABREU \& FIGUEIRA NETO (1997). Esse fato deve-se ao hábito do gato se lamber, pois sua língua é abrasiva, comprometendo a sutura de pele, como citou ARAÚJO (1998).

\section{BRASMER (1971) citou o} desenvolvimento de seroma no subcutâneo, após o implante de material prostético, sendo totalmente reabsorvido após 20 dias de pós-operatório, fato não ocorrido neste experimento.

\section{CONCLUSÃO}

Mediante os resultados obtidos no presente experimento, é possível concluir que o implante heterólogo de cartilagem auricular preservado em glicerina a $98 \%$, é indicado para a reparação de defeitos na parede torácica, cujo defeito abranja até $9 \mathrm{~cm}^{2}$ em gatos.

\section{REFERÊNCIAS BIBLIOGRÁFICAS}

ABREU, L.M. ; FIGUEIRA NETO, J.B. Avaliação dos fios categute e vicryl em suturas internas de gatos. 1997. 19f. Monografia (Graduação em Medicina Veterinária) - Universidade Federal de Uberlândia.

ALVARENGA, J. Possibilidades e limitações da utilização de membranas biológicas preservadas em cirurgia. In: DALECK, C.R. Tópicos em cirurgia de cães e gatos. Jaboticabal : Fundação de Estudos e Pesquisas em Agronomia - Universidade Estadual Paulista de Jaboticabal, 1992. p.33-39.

ARAÚJO, E. Análise da evolução da cicatrização de feridas cirúrgicas suturadas com fio seda e náilon, em gatos. 1998. 24f. Monografia (Graduação em Medicina Veterinária) Universidade Federal de Uberlândia.

ARONSOHN, M. Diafragmatic advancement for defects of the caudal thoracic wall in the dog. Veterinary Surgery, Philadelphia v.13, p.26-28, 1984.

BONATH, K.H. Thoracic wall closure: toracic closure. In: Complications in small animal surgery. Baltimore : Willians \& Wilkins, 1996. Cap. 8, p.229-239.

BRASMER, T.H. Thoracic wall reconstruction in dogs. Journal American of Veterinary Medical Association, New York, v.159, n.12, p.1758-1762, 1971

BRIGHT, R.M. Parede torácica: Reconstrução da parede torácica utilizando-se tela de marlex. In: Cirurgia dos pequenos animais. 2. ed. São Paulo : Roca, 1986. Cap.21, p.307-311.
BRIGHT, R.M. Uso de implantes de malha para a reconstrução de defeitos da parede torácica. In: BOJRAB, M.J. Técnicas atuais em cirurgia de pequenos animais. 3.ed. São Paulo : Roca, 1996. Cap.23, p.341-343.

BRIGHT, R.M.; BIRCHARD, S.J.; LONG, G.G. Repair of thoracic wall defects in the dog with an omental pedicle flap. Journal of the American Animal Hospital Association, New York, v.18, p.277-282, 1982 .

CHEHUEN NETO, J.A. et al. Restauração traqueal com enxerto cartilaginoso autólogo de pavilhão auricular: estudo experimental em coelhos. Acta Cirúrgica Brasileira, São Paulo, v.6, n.4, p.169-176, 1991.

CONTESINI, E.A. et al. Reparação traqueal em cães: transplante autógeno vs implante homógeno conservado em glicerina a $98 \%$ de cartilagem da pina. Ciência Rural, Santa Maria, v.31, n.4, p.633-637, 2001a.

CONTESINI, E.A. et al. Influência antibiótica no reparo tardio com uso da pina auricular conservada em glicerina a $98 \%$ em cães. In: CONGRESSO BRASILEIRO DE CLÍNICOS VETERINÁRIOS DE PEQUENOS ANIMAIS, 22., 2001b, Fortaleza. Anais... Fortaleza : Ciência animal, 2001. 289p. p.166.

DELAY, E. et al. Reconstruction de pleine épaisseur de la paroi thoracique antérieure par lambeau osteo-musculo-cutané de grand dorsal. Annales de Chirurgie Plastique Esthetique, French, v.39, n.2, 204-210, 1994.

FEENEY, D.A. et al. Malignant neoplasia of canine ribs: clinical, radiographic, and patologic findings. Journal of the American Animal Hospital Association, New York, v.180, p.927-933, 1982.

FOSSUM, T.W. Surgery of the lower respiratory system: lungs and thoracic wall. In:

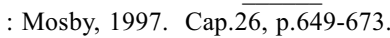

ORTON, E.C. Parede torácica. In: SLATTER, D. Manual de cirurgia de pequenos animais. 2.ed. São Paulo : Manole, 1998. V.1, cap.31, p.457-468.

ORTON, E.C. Disorders of the toracic wall. In: Small animal toracic surgery. Willians \& Wilkins : Baltimore, 1995. Cap.6, p.78-81.

PIGATTO, J.A.T. et al. Esofagoplastia cervical em caninos com enxerto homólogo de cartilagem conchal preservada em glicerina. Ciência Rural, Santa Maria, v.28, n.4, p.617-621, 1998.

PIGOSSI, N. et al. Estudo experimental e clínico sobre o emprego, como implante, da dura-mater homógena conservada em glicerina à temperatura ambiente. Revista da Associação Médica Brasil, São Paulo, v.17, n.8, p.263-278, 1971

RAISER, A.G. et al. Protocolo da anti-sepsia e implantação para homoimplante ortotópico de tendão calcâneo, conservado em glicerina a $98 \%$ em cães. In: CONGRESSO BRASILEIRO DE CIRURGIA E ANESTESIOLOGIA VETERINÁRIA, 4., 2000, Goiânia. Anais... Goiânia : UFG, 2000. 296p. p. 105 .

RUIZ, A.A. et al. Sarcomas de la pared torácica. Ressección y reconstrucción. Revista Instituto Nacional de Cancerologia, México, v.43, n.4, p.189-193, 1997. 